\title{
Development of wireless vertical bar spinner combat robot
}

\author{
Amirul Syafiq Sadun ${ }^{1}$, Jamaludin Jalani², Suziana Ahmad ${ }^{3}$, Amiera Saryati Sadun ${ }^{4}$, \\ Sumaiya Mashori ${ }^{5}$ \\ 1,2,5 Faculty of Engineering Technology, Universiti Tun Hussein Onn Malaysia, Malaysia \\ ${ }^{3}$ Fakulti Teknologi Kejuruteraan Elektrik dan Elektronik, Universiti Teknikal Malaysia Melaka, Malaysia \\ ${ }^{4}$ Kolej Komuniti Temerloh, Malaysia
}

\begin{abstract}
Article Info
Article history:

Received Sep 3, 2019

Revised Nov 5, 2019

Accepted Nov 19, 2019

Keywords:

Combat robot

DC brush motor

Motor drivers

Radio control

ABSTRACT

Recently, combat robot competition has become one of the most famous engineering competitions among schools and universities. The robots are usually built with a destructive weapon, which can immobilize or disable opponent's robot and win the match. Despite the variety of robot design and concept, the trend has shown that most of the local contestant tend to design a horizontal axis weapon type. In this project, a wireless vertical axis bar spinner combat robot is designed and developed for the 3rd Malaysia Combat Robot Competition which was held at National Science Centre (PSN) in 2017. The robot is controlled using radio control (RC) and powered by a highly discharge $22.2 \mathrm{~V}$ Lithium Polymer (LiPo) chemical battery. Furthermore, related analysis has been conducted to meet the design and performance requirement of the competition. With the DC brush motor and thick metal bar rotating in vertical axis, the robot has proven to produce high power, torque and speed during the competition.
\end{abstract}

Copyright $@ 2020$ Institute of Advanced Engineering and Science. All rights reserved.

Corresponding Author:

Amirul Syafiq Sadun

Faculty of Engineering Technology,

Universiti Tun Hussein Onn Malaysia,

Johor, Malaysia

Email: amirul@uthm.edu.my

\section{INTRODUCTION}

Robot becomes interest topic and the technology of the robot increases rapidly. Robot is a machine in which capable to carry a simple task to a complex series action in automatically and simultaneously. Thus, robot technology is used in many fields such as agriculture for weed controlling, plucking and others [1-4], medicine with human interaction [5-7], manufacturing [8,9] and others. Based on these studies, robot can make the task easier and reduce the human power in different fields.

One of the interest topics in robot is a robot competion. The robot competitions became popular nationwide with variety of theme including the combat robot [10], underwater robot [11, 12], human-robot interaction competition $[13,14]$ etc. Combat robot competition is a kind of competitive race between two or more customize robot combat in a provided specific game field. The main design for a combat robot can be divided into three which are weapon, chassis and wheels [15]. Those customs-build machines used various methods or types of weapon to immobilize or disable the opponent's robot and win the match. The robot competition challenges the skill, design, robustness and others technology in which related to robot. Thus, robot competitions give advantages in robot development progress [16].

Nowadays, most of the robots are controlled by using wireless technology [17, 18] including wireless sensor $[19,20]$ for different purpose. In combat robot, the wireless technology purposely uses for safely controlling the attack movement in the game field. The control techniques in combat robot includes the drive and weapon motor with variable speed control. The variable speed features enable the user to control the power usage while maintaining the robot performance. The robot's weapon mechanism can be controlled 
according to the attack strategy. The strategy includes controlling the time of motor operation to flip over opponent's robot, rotational weapon torque, and pneumatic piston to extend and retract. It also proves that the players' skills also contribute in determining the robot efficiency in term of attack and defense. It takes a lot of practices and focus to handle and maneuver the robot. Hence, the combination of both human and robot design factors would produce a powerful combat robot.

An energy supply and recharching for robot is one of the main parts of the robot. Many methods had been studies to make sure the sustainable add maintenance of the power supply. Thus, wireless energy transfer is introduced in the robot [20] to overcome the problem of charging problem for the robot. Wireles energy transfer or wireless power transfer (WPT) is a technology to transfer power without wire. It is one of the solutions for easier charging for moveable thing such as robot, vehicle [21] and eithers. Recently, inductive power transfer [22] and capacitive power transfer [23] are two methods in which become famous in wireless power transfer. Deployment the wireless power transfer in a robot system increases the effectiveness of robot in term of power supply [24-25]. Thus, the combat robot can be charged without wire in efficient way during the competion.

The work in this paper focusing on the design and development of a robot for Malaysia Combat Competion. The robot was design based on the criteria in which outline by the organizer [8].

\section{THE COMBAT ROBOT COMPETITION}

Several types of weapons had been used in previous 2nd Malaysia Combat Robot Competition (in 2016) such as push board, flipper, horizontal axis rotating drum, and horizontal axis rotating blade as shown in Figure 1.

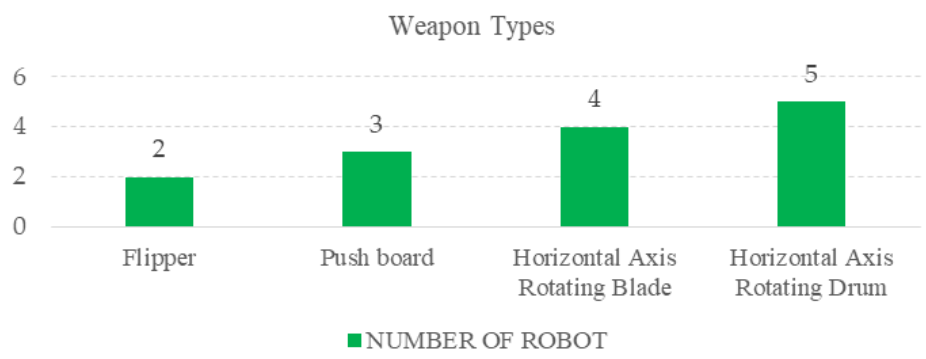

Figure 1. Trends of weapon types

From the trends shown in Figure 1, it is concluded that most contestants (which is about 64\% from 14 finalists) developed horizontal axis rotating drum or blade weapon type. This may be due the fact that these designs can produce a robot with a low center of gravity. Hence the stability of the robot is ensured during the collision of impact with opponent.

The push board type of weapon depends entirely on defense mode to shield from opponent's attack. This type of weapon consists of a solid and compact design, which is not easily immobilized. The robot attack mode utilized the powerful drive motor to push the opponent. The key to winning the match using this type of weapon is by pushing the opponent's robot in the death pit or by flipping opponent's robot. However, the main disadvantage is that the push board could not be designed with a lower structure (to avoid being stuck on the game field) and only produces an attacking power no more than the drive momentum of the robot

On the other hand, the combat robot with a flipper type of weapon can only win a match by flipping over the opponent's robot and immobilize it. This type of weapon needs to be powerful enough to flip over the opponent's robot (i.e. a minimum of $30 \mathrm{~kg}$ of weight). Without the high flipping force, the weapon seems useless. With the right amount of force and good controlling skills, this type of weapon will present a major advantage since it can easily immobilize its opponent. However, the flipper disadvantage is it could be easily damaged when hit by a rotating type weapon.

The horizontal axis rotating drum type of weapon is designed to disable the opponent's robot by damaging the parts and weapon of the opponent's robot. The advantages of this design are the fast-rotating weapon can be fixed as low as touching the floor with destructive ability. However, the disadvantage is the high-speed rotating drum require a high current to operate, especially when the current spikes during the moment of impact. This might cause the battery and drive to overload and damage the circuit board. 
The horizontal axis rotating blade type of weapon have the working principle similar to the drum type. The key difference is in the thinner weapon shape with a higher speed (RPM). The weapon can be used to flip over the opponent while destroying the structures. The higher rotating speed enables the robot to attach with maximum torque while speeding towards the opponent. The disadvantage of this type of weapon is it can be easily damaged by horizontal axis rotating drum type of weapon and the momentum of rotating blade is limited due to the size. In this project, the design and development of a combat robot with vertical axis weapon is explored for the purpose of participating in the 3rd Malaysia Combat Robot Competition which was held in 2017.

\section{DESIGN SCOPES}

The wireless remote combat robot was designed to immobilize the opponent's robot in a combat robot competition. There are several criteria that are followed to meet the competition build rules such as:

a) Electronic components are studied and applied to the desired movement controlling by radio control.

b) The wireless remote combat robot is operated using Lithium Polymer (LiPo) battery.

c) The wireless remote combat robot will be designed to have a longer range rotational weapon in the front part of the robot.

d) The size of the robot cannot exceed the following dimension: (800mm Length $\mathrm{x} 800 \mathrm{~mm}$ Width $\mathrm{x} 500 \mathrm{~mm}$ Height) and maximum weight is $30 \mathrm{~kg}$.

\subsection{Structure Design}

The mechanical design of combat robot has been discussed in this section using the SketchUp software. The main structure of the combat robot is shown in Figure 2.

Figure 2 shows the main body of the robot which consists of guard to protect the body, wheels for robot movement, chain for transferring the mechanical energy from the weapon's motor to the shaft, vertical axis shaft for spinning and stabilizing the spinner bar, and spinner bar as the weapon for attack opponent's robot. The dimension of the robot is $800 \mathrm{~mm} \times 500 \mathrm{~mm} \times 250 \mathrm{~mm}$. In addition, the mechanical design includes the frame of body, fixed bracket for weapon's and the wheel's motors as shown in Figure 3.

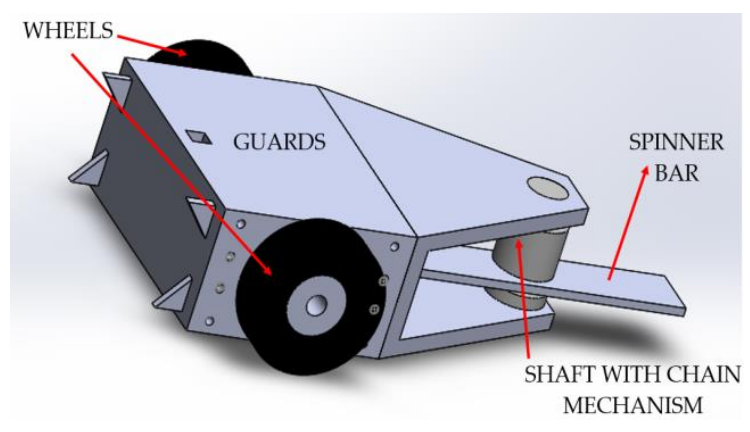

Figure 2. 3D design of combat robot

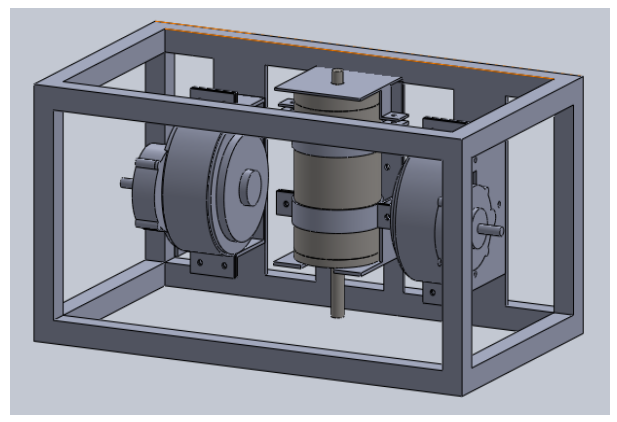

Figure 3. 3D design for combination of body frame and fixed brackets

For the mechanism of this vertical axis bar spinner robot, it mainly operates by the weapon's motor. Motor converts the electrical energy to mechanical energy, with the help of metal chain, it transfers the mechanical energy from the motor to the shaft of the spinner bar. With the weight of the fast spinning bar, it creates a high momentum and force to destruct opponent's combat robot. Figure 5 and Figure 6 shows the final product of the wireless remote bar spinner combat robot namely FTK17, while Figure 7 illustrates the combat robot during the competition in 2017. 


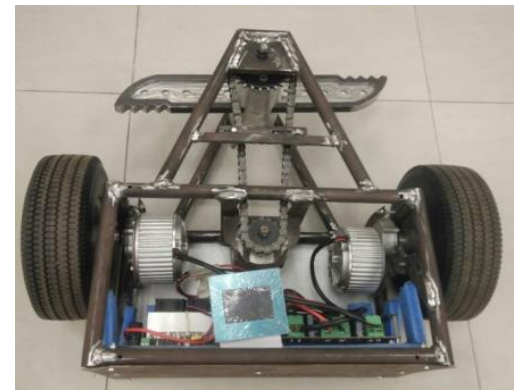

Figure 5. Final product (inside look)

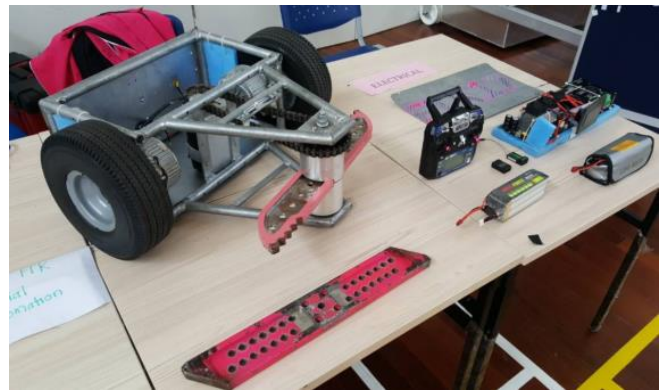

Figure 6. Final product (all parts)

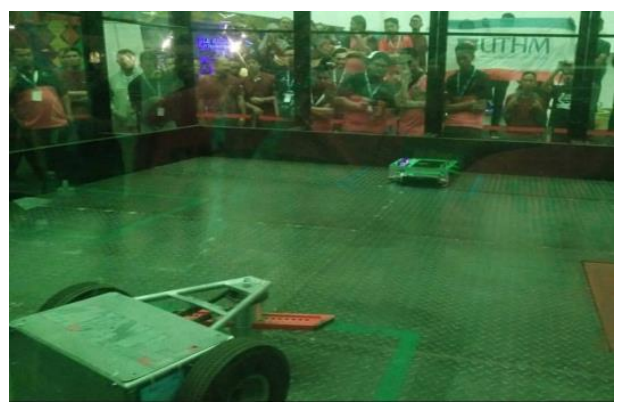

Figure 7. FTK17 in Malaysia combat robot competition 2017

\section{ELECTRICAL AND ELECTRONIC DESIGN}

The radio-based controller is used in the design to control the robot. Radio transmitter is transmitting the signal wirelessly and received by the radio receiver. A radio receiver with the input of $+5 \mathrm{~V}$ power supply is used for operation purpose. The $22.2 \mathrm{~V} \mathrm{LiPo}$ batteries supplied the power to both wheel motor drive and weapon's motor drive. When a radio receiver received the signal from radio transmitter, it is transferring the signal to both motor drives to control the motors. As the output, the direction of the robot is triggered by the wheel motor drive while weapon spinning speed is triggered by the weapon's motor drive. Figure 8 shows the flowchart of the block diagram of combat robot.

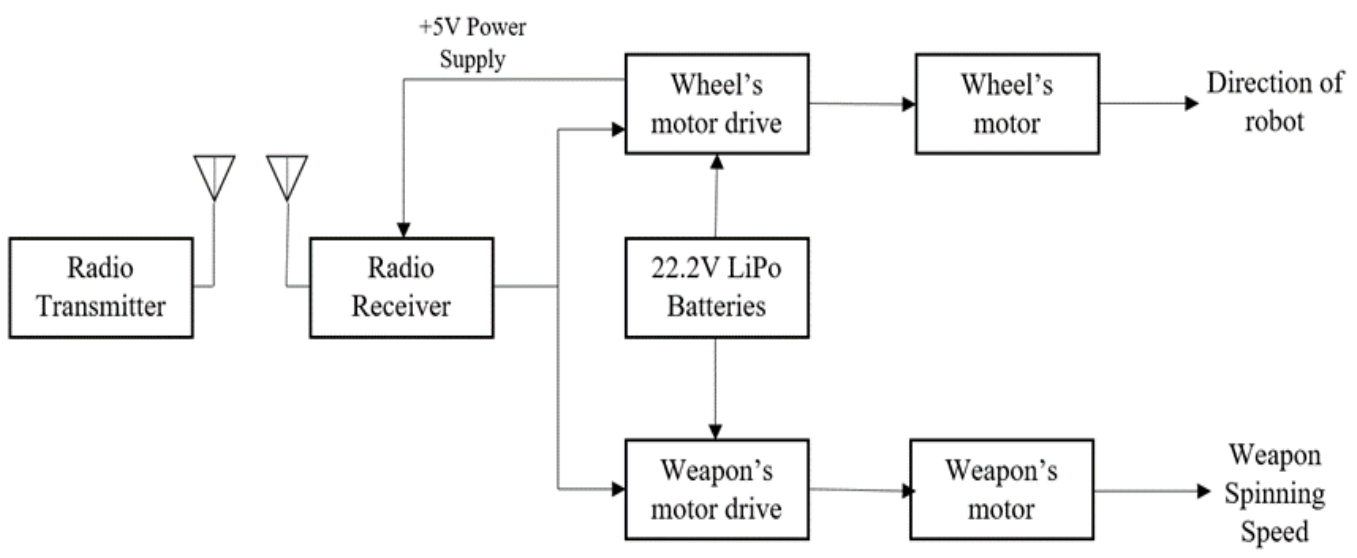

Figure 8. Block diagram of combat robot

There are three frequencies that can be applied and allowed for combat robot control which are 40 $\mathrm{MHz}, 2.4 \mathrm{GHz}$, and $459 \mathrm{MHz}$ However, the organizer of the 3rd Malaysia Combat Robot Competition recommends the $2.4 \mathrm{GHz}$ as the radio control's frequency. Thus, the design is focused on $2.4 \mathrm{GHz}$ radio control. 
The benefit of $2.4 \mathrm{GHz}$ frequency radio control is lower interference. When remoting the combat robot, this frequency lets the radio control out of the frequencies of any sorts of noise that can be caused due to electronic components. This eliminates any sort of interference. The next is it has high performance in terms of fast response of the signal. Since the high frequency can transmit high data rate, the response is faster compared to other low frequencies. During robot combat, having a fast response communication between transmitter and receiver is important. Needless to say, $2.4 \mathrm{GHz}$ radio control has been chosen as the frequency of the radio control device. As a result, RC transmitter with FS-iA6B receiver are chosen as the radio control set of this project.

\section{RESULTS}

Radio control is set with the stick mode. Channel 1 and Channel 2 as joysticks are connected to the Smart Drive Duo-60 for wheel's motor control. Wheel's motors can be controlled at the same time. Direction of wheel's motor is set to run both in the same direction for forward and backward while different direction to turn right and turn left. Wheel's motors are placed on both right side and left side; thus, it is reversed in all directions.

Transmitter of radio control can be set to reverse in Channel 1 and 2 making sure the wheel's motor can run in the same directions while placing at both right and left sides. Channel 3 as a throttle is connected to the Smart Drive 160 for weapon's motor control. It can give a continuous and stable signal for control the speed of weapon's motor. Maximum signal represents the maximum speed of the weapon's motor and so on. During the combat, combat robot must be stable enough, full speed movement is not suitable to control, only 20 percent $(20 \%)$.

The performance of both weapons and wheels motor is analyzed based on the speed and its torque. For the speed of the motor, measurement is in unit of round per minutes (RPM) is conducted using digital achometer. The current draws from the motor driver is measured using Clamp multi-meter in units of ampere (A). The specification of the combat robot is summarized by Table 1 . The total weight of the robot is $29.98 \mathrm{~kg}$.

\begin{tabular}{cc} 
Table 1. Characteristic of Combat Robot \\
\hline Item & Measurement \\
\hline Wheel's Motor & $492.6 \mathrm{rpm}$ \\
Weapon's motor & $5492.4 \mathrm{rpm}$ \\
Current of Wheel's Motor & $0.51 \mathrm{~A}$ \\
Current of Weapon's motor & $41.07 \mathrm{~A}$ \\
Weight & $29.98 \mathrm{~kg}$ \\
\hline
\end{tabular}

After the completion of the design and development stages, the robot had been tested and evaluated during the 3rd Malaysia Combat Robot Competition on 4th October 2017. Despite winning the first four matches, it had been defeated in the fifth match during Quarter Final (Top Eight). The main reason of the defeat is because of the push button switch killed the circuit when it was dropped on the floor during the match. The spring inside the switch has been compressed by high momentum of force from the robot when it drops on the floor. It is then suggested that replace a screw able switch to prevent this kind of defeat reason in the future.

\section{CONCLUSION}

The objectives of this project have been achieved. Based on the results, the total weight of the robot is $29.98 \mathrm{~kg}$, with dimensions $755 \mathrm{~mm} \times 640 \mathrm{~mm} \times 260 \mathrm{~mm}$. This wireless remote bar spinner combat robot is able to move in 4 directions, which are forward, backward, left and right and controlled by RC transmitter. The movement speed of this robot is $1.34 \mathrm{~ms}-1$. The speed of the weapon is also controlled by RC transmitter. There is a gear ratio 13:7 transfer the energy from the motor to spinning shaft. The speed of the spinning bar is about $2957 \mathrm{RPM}$. The torque transfer to the spinning bar is around $5.7 \mathrm{Nm}$. For the batteries performance, there is $0.51 \mathrm{~A}$ current consume by two dc scooter motor (wheels), and the batteries can last for 705.9 mins. While for the weapon DC motor consume 41.07A to spin the metal bar at high speed, and the batteries can last for 8.8 mins. It is acceptable for the batteries supply to weapon to last for only 8.8 mins since the match of the combat robot is only for 5 mins. Besides, all the mechanical parts are performing optimally in the combat robot competition. The only drawback is the shaft of the weapon will be bent if it hit a thick metal. However, that does not affect too much on the weapon performance. 


\section{REFERENCES}

[1] P.Lottes, M. Hoeferlin, S. Sander, M. Müter, P. Schulze and L. C. Stachniss, "An effective classification system for separating sugar beets and weeds for precision farming applications," 2016 IEEE International Conference on Robotics and Automation (ICRA), Stockholm, 2016, pp. 5157-5163.

[2] S. Hussmann, F. J. Knoll, A. Meissner and T. Holtorf, "Development and evaluation of a low-cost delta robot system for weed control applications in organic farming," 2019 IEEE International Instrumentation and Measurement Technology Conference (I2MTC), Auckland, New Zealand, 2019, pp. 1-5

[3] H. Yaguchi, K. Nagahama, T. Hasegawa and M. Inaba, "Development of an autonomous tomato harvesting robot with rotational plucking gripper," 2016 IEEE/RSJ International Conference on Intelligent Robots and Systems (IROS), Daejeon, 2016, pp. 652-657.

[4] X. Gao et al., "Review of Wheeled Mobile Robots' Navigation Problems and Application Prospects in Agriculture," in IEEE Access, vol. 6, pp. 49248-49268, 2018

[5] G. Peleka et al., "RAMCIP - A Service Robot for MCI Patients at Home," 2018 IEEE/RSJ International Conference on Intelligent Robots and Systems (IROS), Madrid, 2018, pp. 1-9

[6] L. Peternel, N. Tsagarakis and A. Ajoudani, "A Human-Robot Co-Manipulation Approach Based on Human Sensorimotor Information," in IEEE Transactions on Neural Systems and Rehabilitation Engineering, vol. 25, no. 7, pp. 811-822, July 2017.

[7] Y. Wang and S. Wang, "Development of an excretion care support robot with human cooperative characteristics," 2015 37th Annual International Conference of the IEEE Engineering in Medicine and Biology Society (EMBC), Milan, 2015, pp. 6868-6871.

[8] J. A. Marvel, "Sensors for safe, collaborative robots in smart manufacturing," 2017 IEEE SENSORS, Glasgow, 2017, pp. 1-3.

[9] B. Sadrfaridpour and Y. Wang, "Collaborative Assembly in Hybrid Manufacturing Cells: An Integrated Framework for Human-Robot Interaction," in IEEE Transactions on Automation Science and Engineering, vol. 15, no. 3, pp. 1178-1192, July 2018.Myrobotz,

[10] "MALAYSIA COMBalaysia-combatrobot-is-robotic.html. [Accessed: 01-Apr-2017].

[11] M. Arima, K. Ishii, T. Ura, T. Maki and H. Kondo, "Evolution and prospects of underwater robot competition in Japan," OCEANS 2015 - Genova, Genoa, pp. 1-6, 2015.

[12] J. Yu, C. Wang and G. Xie, "Coordination of Multiple Robotic Fish With Applications to Underwater Robot Competition," in IEEE Transactions on Industrial Electronics, vol. 63, no. 2, pp. 1280-1288, Feb. 2016.

[13] A. K. Pandey, L. de Silva and R. Alami, "A novel concept of Human-Robot competition for evaluating a robot's reasoning capabilities in HRI," 2016 11th ACM/IEEE International Conference on Human-Robot Interaction (HRI), Christchurch, pp. 491-492, 2016

[14] D. Calvaresi et al., "A framework based on real-time OS and multi-agents for intelligent autonomous robot competitions," 2016 11th IEEE Symposium on Industrial Embedded Systems (SIES), Krakow, pp. 1-10, 2016

[15] M. Vinciguerra and T. Thompson, "A procedural generation framework for a robot construction game," 2015 7th Computer Science and Electronic Engineering Conference (CEEC), Colchester, pp. 213-218, 2015.

[16] K. Sasabuchi, H. Yaguchi, K. Nagahama, S. Hori, H. Mizohana and M. Inaba, "The Seednoid Robot Platform: Designing a Multipurpose Compact Robot From Continuous Evaluation and Lessons From Competitions," in IEEE Robotics and Automation Letters, vol. 3, no. 4, pp. 3983-3990, Oct. 2018.

[17] S.Caccamo, R. Parasuraman, L. Freda, M. Gianni and P. Ögren, "RCAMP: A resilient communication-aware motion planner for mobile robots with autonomous repair of wireless connectivity," 2017 IEEE/RSJ International Conference on Intelligent Robots and Systems (IROS), Vancouver, BC, 2017, pp. 2010-2017.

[18] M. Chowdhury and M. Maier, "Local and Nonlocal Human-to-Robot Task Allocation in Fiber-Wireless MultiRobot Networks," in IEEE Systems Journal, vol. 12, no. 3, pp. 2250-2260, Sept. 2018.

[19] H. Li and A. V. Savkin, "Wireless Sensor Network Based Navigation of Micro Flying Robots in the Industrial Internet of Things," in IEEE Transactions on Industrial Informatics, vol. 14, no. 8, pp. 3524-3533, Aug. 2018.

[20] U. Baroudi, "Robot-Assisted Maintenance of Wireless Sensor Networks Using Wireless Energy Transfer," in IEEE Sensors Journal, vol. 17, no. 14, pp. 4661-4671, 15 July15, 2017.

[21] M. R. Barzegaran, H. Zargarzadeh and O. A. Mohammed, "Wireless Power Transfer for Electric Vehicle Using an Adaptive Robot," in IEEE Transactions on Magnetics, vol. 53, no. 6, pp. 1-4, June 2017, Art no. 7205404.

[22] Z. Zhang and K. T. Chau, "Homogeneous Wireless Power Transfer for Move-and-Charge," in IEEE Transactions on Power Electronics, vol. 30, no. 11, pp. 6213-6220, Nov. 2015.

[23] F. Lu, H. Zhang, and C. Mi, "A review on the recent development of capacitive wireless power transfer technology," Energies, vol. 10, no. 11, 2017.

[24] R. Narayanamoorthi, A. V. Juliet and B. Chokkalingam, "Frequency Splitting-Based Wireless Power Transfer and Simultaneous Propulsion Generation to Multiple Micro-Robots," in IEEE Sensors Journal, vol. 18, no. 13, pp. 5566-5575, 1 July1, 2018

[25] J. Gao et al., "Design and Testing of a Motor-Based Capsule Robot Powered by Wireless Power Transmission," in IEEE/ASME Transactions on Mechatronics, vol. 21, no. 2, pp. 683-693, April 2016. 


\section{BIOGRAPHIES OF AUTHORS}
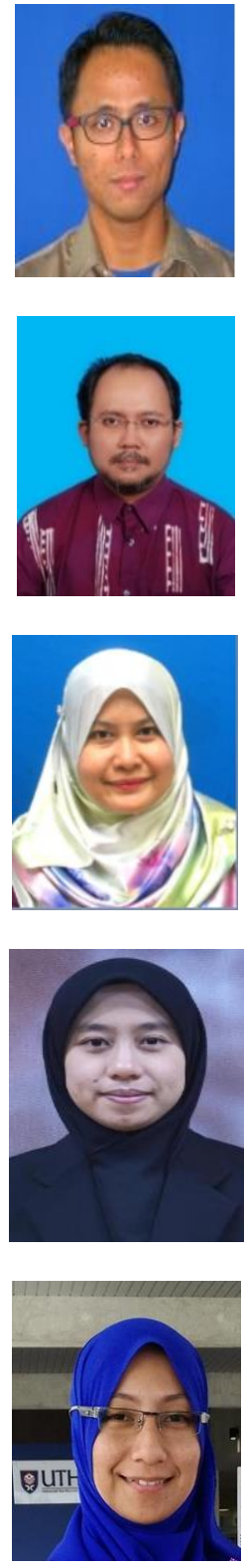

Amirul Syafiq Sadun graduated in Bachelor Degree of Electrical Engineering and Master Degree in Technical Education (Electrical Engineering) from Universiti Tun Hussein Onn Malaysia (UTHM), Johor. He had 4 years of experienced as Engineer in Design and Engineering Department for Japanese company name Alps Electric (M) Sdn. Bhd. He is now a Lecturer in Universiti Tun Hussein Onn Malaysia (UTHM) Kampus Pagoh.

Jamaludin Jalani is an Associate Professor at the Faculty of Engineering Technology, Universiti Tun Hussein Onn Malaysia (UTHM). He obtained his PhD at University of Bristol, United Kingdom. His research focus on the development of the Humanoid Robot Hand and the Application of Control System. Dr Jamaludin was an Engineer for 4 years in Sharp Manufacturing Malaysia and currently, he is the head of department of the Department Electrical Engineering Technology

Suziana Ahmad was graduated in Bachelor Degree of Electrical Engineering from Universiti Teknologi Malaysia and she obtained her Master Degree in Industrial Electronic \& Control from University of Malaya, Kuala Lumpur. She had experienced as R\&D Electrical Engineer at Panasonic System Networks (M) Sdn. Bhd for few years and she continued her career as Teaching Engineer in Universiti Teknikal Malaysia Melaka and currently she is working as Lecturer in the same university

Amiera Saryati Sadun was graduated in Bachelor Degree of Electrical Engineering from Universiti Tun Hussein Onn Malaysia (UTHM), Johor. She had 2 years of experienced as Engineer in Design Department for Japanese name Alps Electric Sdn Bhd \& 9 years' experience as a lecturer at Kolej Komuniti Temerloh, Kementerian Pendidikan Tinggi in Building Maintanance Course.

Sumaiya binti Mashori was graduated in Bachelor Degree of Electrical Engineering from UTHM and Master of Engineering (Electrical Power) from UTM, Johor. She had 3 years of working experience as a R\&D Electrical Engineer at Panasonic Communication (M) Sdn Bhd. Currently, she is a Teaching Engineer in Universiti Tun Hussein Onn Malaysia (UTHM) Kampus Pagoh. 